\title{
Contribuições da psicologia discursiva para o campo da comunicação sobre riscos em saúde
}

\section{Contributions of discursive psychology to the field of risk communication in health}

\section{Contribuciones de la psicología discursiva hacia el campo de la comunicación sobre riesgos en salud}

\author{
Mary Jane Paris Spink \\ mjspink@pucsp.br | http://orcid.org/o000-0003-1672-505X
}

\author{
${ }^{1}$ Pontifícia Universidade Católica de São Paulo, Pró-Reitoria de Pós-Graduação, Programa de Pós-Graduação em \\ Psicologia: Psicologia Social. São Paulo, SP. Brasil. \\ a Doutorado em Psicologia Social pela University of London.
}

\section{Resumo}

A comunicação no campo da saúde é um imperativo ético e, no caso da comunicação sobre riscos, seguiu longa trajetória, que levou de modalidades unidirecionais de transmissão de informação de especialistas para a população à paulatina participação do público, de modo a incentivar a alfabetização nesse âmbito como precondição para modificar práticas visando à promoção da saúde. Na perspectiva das ciências sociais, em um primeiro momento, a contribuição maior veio da psicologia cognitiva, sobretudo das pesquisas baseadas na psicometria. A psicologia social entra nesse campo mais tardiamente, sendo objetivo desta nota de conjuntura pontuar as contribuições dos estudos sobre linguagens dos riscos, mais especificamente a respeito das distintas tradições discursivas, a fim de entender os processos de produção de sentido sobre riscos na vida cotidiana, propondo que a mediação psicossocial é relevante para romper com a dicotomia entre especialistas e leigos.

Palavras-chave: Linguagem dos riscos; Comunicação; Psicologia discursiva; Alfabetização em saúde; Práticas discursivas.

\begin{abstract}
Communication in the field of health is an ethical imperative, and in the case of risk communication, it has followed a long path that has led from unidirectional modalities of transmitting information from specialists to the population to the gradual participation of the public to encourage health literacy as a precondition for modifying practices aiming at health promotion. From the perspective of the social sciences, the major contribution first came from cognitive psychology, especially from psychometry-based research. Social psychology enters this field much later, and the objective of this conjuncture note is to highlight the contributions of research on risk languages, more specifically in regard to the different discursive traditions, as a way of understanding the processes of production of meaning about risks in daily life, suggesting that psychosocial mediation is relevant to ending the dichotomy between experts and lay people.
\end{abstract}

Keywords: Risk languages; Communication; Discursive psychology; Health literacy; Discursive practices. 


\section{Resumen}

La comunicación en el campo de la salud es un imperativo ético y, en el caso de la comunicación sobre riesgos, siguió una larga trayectoria que llevó de modalidades unidireccionales de transmisión de información de especialistas para la población a la paulatina participación del público para incentivar la alfabetización en salud como condición imprescindible de la modificación de prácticas para la promoción de la salud. En la perspectiva de las ciencias sociales, en un primer momento la contribución mayor ha venido de la psicología cognitiva, sobre todo de las investigaciones basadas en la psicometría. La psicología social entra en ese campo más tardíamente y el objetivo de esta nota de coyuntura es resaltar las contribuciones de los estudios sobre lenguajes de los riesgos, de una manera más específica sobre las distintas tradiciones discursivas, de forma que se pueda entender los procesos de producción de sentido sobre riesgos en la vida cotidiana, proponiendo que la mediación psicosocial es relevante para romper con la dicotomía entre especialistas y legos.

Palabras clave: Lenguaje de los riesgos; Comunicación; Psicología discursiva; Alfabetización en salud; Prácticas discursivas.

Contribuição dos autores: a autora é responsável por todo o texto.

Declaração de conflito de interesses: não há.

Fontes de financiamento: não há.

Considerações éticas: não há.

Agradecimentos/Contribuições adicionais: não há.

Histórico do artigo: submetido: 12 fev. 2019 | aceito: 14 fev. 2019 | publicado: 29 mar. 2019

Apresentação anterior: não houve.

Licença CC BY-NC atribuição não comercial. Com essa licença é permitido acessar, baixar (download), copiar, imprimir, compartilhar, reutilizar e distribuir os artigos, desde que para uso não comercial e com a citação da fonte, conferindo os devidos créditos de autoria e menção à Reciis. Nesses casos, nenhuma permissão é necessária por parte dos autores ou dos editores. 
Embora o campo da comunicação e informação em saúde seja muito mais abrangente, o foco, neste breve ensaio, é a comunicação sobre riscos, área na qual tenho longa trajetória de pesquisa. A comunicação sobre riscos, por sua vez, integra o campo da 'análise dos riscos' que, segundo alguns autores (entre eles, Hood, Jones, Pidgeon, Turner e Gibson ${ }^{1}$, assim como Renn²) tem início na década de cinquenta do século $\mathrm{XX}$, no contexto dos riscos associados à energia nuclear. Desde cedo, esse campo englobou três áreas de especialidade: o cálculo dos riscos (risk assessment), a percepção dos riscos pelo público e a gestão dos riscos. Mais recentemente, a análise dos riscos passou a incorporar também a 'comunicação sobre riscos', tendo em vista que a participação pública se tornou elemento imprescindível no controle social dos riscos.

A comunicação sobre riscos tem por objetivo transmitir informações, para que a população possa tomar decisões, seja no caso de emergências (por exemplo, no caso de desastres ambientais), seja no contexto da promoção da saúde (como no caso das vacinas). Além disso, é um imperativo ético, embora também enfrente desafios. Como imperativo ético, parte do pressuposto que as pessoas têm direito à informação sobre questões que as afetam. Nesse enquadre, as práticas de comunicação sobre risco, em geral, se afastaram das abordagens tecnocráticas ${ }^{3}$, pautadas na mera transferência de informação derivada de especialistas ao público, ou seja, em modelos unidirecionais de comunicação.

Baruch Fischhoff 4 traça a história da comunicação sobre riscos com base em oito estágios de desenvolvimento que, a bem dizer, convivem lado a lado ainda hoje. No primeiro estágio, bastava fazer cálculos certos e gerenciá-los adequadamente. No segundo, se tornou imprescindível informar tais números à população, independentemente de ter adquirido as necessárias habilidades em comunicação. No terceiro, a comunicação passou a ser acompanhada de explicação sobre os dados, abrindo espaço para o que hoje se denomina "alfabetização em saúde" . O quarto estágio incorporou a questão da comparação com riscos já incorridos ou conhecidos. O quinto abriu-se às estratégias de persuasão, expondo benefícios potenciais dos riscos que acompanham determinadas tecnologias. O sexto estágio do modelo de Fischhoff 4 , intitulado "all we have to do is treat them nice" [tudo o que devemos fazer é tratá-los bem] concerne ao reconhecimento de que é preciso adquirir competência em comunicação.

Obviamente, nas seis fases iniciais, a comunicação é unidirecional, sofisticando-se apenas a noção de audiência. Mas, no sétimo estágio, o que está em pauta é o reconhecimento de que é necessário envolver o público nas decisões que envolvem riscos coletivos, ou seja, torná-lo parceiro na tomada de decisões. Passaram-se a adotar abordagens que, em última instância, nos modelos mais próximos a uma democracia participativa, podem ser entendidas como abordagens de negociação, a exemplo da proposta de fóruns híbridos ${ }^{6}$. Trata-se, neste caso, da participação do público no próprio processo de produção de informação, de espaço propício para a discussão das controvérsias decorrentes de incertezas técnicas ou científicas (as zonas cinzentas de informação) e que possibilitam novas linhas de investigação.

Atualmente, a comunicação sobre riscos enfrenta desafios associados ao desenvolvimento das tecnologias de informação. Em consulta ao tópico sobre comunicação de riscos no site da Organização Mundial de Saúde (OMS)7 , são mencionadas duas mudanças que tornam problemática a comunicação sobre riscos na vertente tradicional de fluxo de informação de instâncias oficiais e de cientistas para o público.

A primeira mudança significativa é que experts e autoridades deixam de ser fontes de informação totalmente confiáveis. Ulrich Beck ${ }^{8}$ propõe que vivemos, hoje, em uma sociedade de risco na qual ocorrem três deslocamentos: (a) Globalização, que se refere à intersecção da ausência e presença, ou ao entrelaçamento de relações sociais e eventos sociais que estão distantes dos contextos locais; (b) Individualização, que decorre dos processos de destradicionalização - transformações que vêm ocorrendo nas instituições tradicionais: família, trabalho, educação, que fazem as biografias se tornarem projetos reflexivos; e (c) Reflexividade, que concerne à suscetibilidade da maior parte dos aspectos da atividade social e das relações 
com a natureza à revisão crônica, à luz de novas informações. É a soma desses deslocamentos que torna as informações 'oficiais' passíveis de serem questionadas.

A segunda mudança apontada no texto disponibilizado no site da $\mathrm{OMS}^{7}$ é quanto às transformações tecnológicas na área da comunicação. Por intermédio de dados da International Telecommunication Union (ITU), para situar a penetração da rede móvel no contexto global, conclui-se que "o número de assinantes da rede de celulares no mundo se aproxima ao número de pessoas na terra”. A situação é semelhante no Brasil - segundo a Pesquisa Nacional por Amostra de Domicílios Contínua (Pnad), divulgada pelo Instituto Brasileiro de Geografia e Estatística (IBGE) ${ }^{9}$, em 2016, a cada dez domicílios no Brasil, sete tinham acesso à internet.

Com maior acesso à internet, as pessoas buscam informações sobre questões de saúde em fontes online e em redes sociais. Porém, esta é uma 'faca de dois gumes', pois, se há maior acesso à informação, há também maior potencial de vigilância. Beck ${ }^{8}$ trata dessa questão com base na discussão sobre a natureza dos mecanismos de gestão de pessoas, sobretudo a gestão da informação numa sociedade destradicionalizada, com mudanças substantivas na natureza da informação e na própria gestão. Para o autor, a informação na sociedade globalizada prescinde das instituições educativas ou as transforma: é um processo contínuo que se dá dentro e fora dos espaços institucionais da educação; é capilar e se difunde por meio das várias tecnologias de informação, mas gera novas formas de vigilância, agora subsumidas pelo controle do estilo de vida e pela monitoração constante dos indicadores de saúde.

Contudo, não se trata apenas da diversidade de informações em circulação, há também outro aspecto que me possibilita trazer para o debate a abordagem que temos desenvolvido sobre linguagem dos riscos ${ }^{10,11}$.

\section{Da percepção dos riscos aos sentidos polissêmicos de risco}

A psicologia cognitiva trouxe muitas contribuições para a área da comunicação sobre riscos, entre elas, a perspectiva psicométrica que tem ainda ampla influência, apesar da paulatina constatação de que percepção sobre riscos não decorre apenas da capacidade cognitiva de processamento de informações: está imbricada em vivências, fatores culturais e formas de hierarquizar riscos.

A pesquisa sobre percepção de risco foi fortemente influenciada pela metodologia proposta nos anos de 1970 pelo Decision Research Group de Oregon, nos Estados Unidos (por exemplo, o trabalho de Slovic, Fischhoff e Lichtenstein ${ }^{12}$.). Nessa abordagem, pede-se às pessoas que classifiquem uma diversidade de perigos. Os dados assim obtidos são processados estatisticamente, mediante técnicas que possibilitam identificar diferentes dimensões dos riscos e fatores psicológicos subjacentes às avaliações feitas. Esse estilo de pesquisa possibilitou que fossem feitos vários estudos transculturais sobre percepção de risco.

Buscou-se nesses estudos incluir dimensões sociais e culturais, especialmente no que diz respeito à disponibilidade de informação sobre riscos na mídia. Entretanto, a revisão dos esforços de pesquisa transculturais acerca da percepção de risco, feita por Boholm ${ }^{13}$ e publicada em 1998, na revista Journal of Risk Analysis, apontou que há necessidade urgente de refinamentos metodológicos e teóricos. Concluiu o autor que as pesquisas transculturais se deparam com pelo menos dois obstáculos: 1) o fato de serem os riscos contextuais, adquirindo diferentes significados em diferentes contextos culturais; 2) de serem eles também sensíveis à experiência, mesmo sendo esta reinterpretada como proximidade com a informação.

Já a psicologia social, mais atenta aos fatores econômicos e sociais, traz como contribuição a esse campo a reflexão sobre produção de sentidos no cotidiano. É nesse enquadre que temos trabalhado com a noção de linguagem dos riscos, desenvolvida no longo percurso de pesquisas que vêm sendo apoiadas pelo CNPq na modalidade de bolsa produtividade: teorizações sobre as tradições de discurso sobre risco (1998-2000); os sentidos de risco na vida cotidiana (2000-2003); o risco como aventura (2003-2006); controle e uso do tabaco (2006-2009) e gestão dos riscos ambientais em situações de vulnerabilidade (2012-2017). 
Como psicóloga social, eu vinha de uma trajetória que mesclava leituras foucaultianas e análise de discurso da vertente construcionista. Para mim, risco não era conceito, noção ou substantivo. Risco era linguagem - a linguagem dos riscos -- e, como toda linguagem, seus usos têm efeitos. Em síntese, os discursos sobre risco definem territórios linguísticos que demarcam campos de gestão nos quais se desenvolvem maneiras específicas de falar sobre riscos e de propor medidas de controle deles. Assim, estamos sugerindo que, no interior de cada campo, se desenham formas de falar sobre riscos que lhe são específicas e estão presas a três tradições de discursos sobre eles.

A primeira tradição, a fala de senso-comum sobre perigos, antecede a emergência da palavra e, portanto, do conceito de risco. São repertórios linguísticos como perigo, ameaça, destino, fatalidade que, embora raramente considerados nas análises de risco, se fazem presentes nos modos de falar sobre risco e nas práticas cotidianas de enfrentamento de riscos.

A segunda tradição, a perspectiva do controle e da disciplina, remete à trajetória histórica dos discursos sobre riscos colados à governamentalidade ${ }^{14}$, ou seja, ao governo de populações e ao risco objetivado pela quantificação. Está relacionada à crescente necessidade de governar populações, a partir da modernidade clássica. Sanciona, portanto, medidas coletivas, destinadas a gerenciar a distribuição e o movimento de pessoas nos espaços físicos e sociais e, como subproduto, referenda processos de disciplinarização da vida privada das pessoas.

A terceira tradição, a perspectiva da aventura, tem afinidade com os campos da economia e dos esportes e herda a positividade da aventura. Agrega um conjunto de repertórios sobre risco, como desafio, adrenalina e ousadia, exibindo conotações que ressignificam correr riscos como prática necessária para alcançar determinados ganhos. Por mera coincidência, circulou na revista The Economist, de 19 de janeiro de 2019, um anúncio da Mishcon de Reya intitulado 'Risk is good: disruption is the law of tomorrow'.

\section{Que utilidade pode ter essa abordagem para o campo da comunicação e informação em saúde?}

Retomando a questão do imperativo ético, é preciso, sim, quando se trata de questões que afetam populações e usuários dos sistemas de saúde, que o público, seja informado sobre questões que afetam suas vidas: por meio de interações face a face (como na consulta médica); pela divulgação midiática ou por meio de fóruns híbridos, com maior possibilidade de participação da população. Mas nada garante que a mensagem recebida será interpretada da maneira como as comunicólogas e os comunicólogos querem. Não se trata apenas de alfabetização em saúde. Todos nós estamos imersos em circuitos de informação que incluem desde trocas entre familiares e amigos como também a maravilhosa aventura de imersão na literatura disponível: dos mangás à literatura dita clássica; do jornalismo cidadão (blogues, YouTube, jornais comunitários) aos sites oficiais da área da saúde. Como tais, possuímos um enorme e rico acervo de informações sobre riscos.

Há que propor, portanto, que, entre comunicadores oficiais e público, haja 'tradutores', isto é, pessoas que dominam tanto a linguagem da ciência quanto a escuta dos múltiplos sentidos atribuídos a riscos e das diversas práticas a eles associadas: quem está em risco e precisa de apoio; quem hierarquiza riscos e por eles opta e, ainda, quem curte estar em risco (o risco desejado). Concluo, assim, com um convite à participação da psicologia social no campo da comunicação e informação em saúde, tendo em vista que, por sua posição híbrida no edifício das ciências sociais, pode se dar ao luxo de buscar trabalhar com a alteridade. 


\section{Referências}

1. Hood CC, Jones D, Pidgeon N, Turner B, Gibson R. Risk management. In: The Royal Society, organizer. Risk: analysis, perception and management. London: The Royal Society; 1992.

2. Renn O. Three decades of risk research: accomplishments and new challenges. J Risk Res.1998; 1(1):49-71.

3. Grabill JT, Simmons WM. Toward a Critical Rhetoric of Risk Communication: Producing Citizens and the Role of Technical Communicators. Tech Commun Quart.1998;7(4):415-41.

4. Fischhoff B. Risk perception and communication unplugged: twenty years of process. Risk Anal. 1995;15 (2):137-45.

5. Nutbeam D. Health literacy as a public health goal: a challenge for contemporary health education and communication strategies into the 21st century. Health Promot Int. 2000;15(3):259-67.

6. Callon M, Lascoumes P, Barthe Y. Acting in an Uncertain World: an Essay on Technical Democracy. Massachusetts: The MIT Press; 2009.

7. World Health Organization. Risk Communication.Genebra; c2019 [cited 2019 nov 11]. Available from: https://www.who.int/risk-communication/background/en/

8. $\quad$ Beck U. Risk society: towards a new modernity. London: Sage; 1993.

9. Instituto Brasileiro de Geografia e Estatística. PNAD contínua trimestral. Rio de Janeiro; 2013 [citado em 2018 jun. 18]. Disponível em: https://biblioteca.ibge.gov.br/index.php/bibliotecacatalogo?view=det alhes\&id $=72421$

10. Spink MJP, Menegon VM. Práticas discursivas como estratégias de governamentalidade: a linguagem dos riscos em documentos de domínio público. In: Iñiguez LR, organizador. Manual de análise do discurso em ciências sociais. Petrópolis, RJ: Vozes; 2004, p. 258-311.

11. Spink MJP. Viver em áreas de risco. São Paulo: Terceiro Nome/Educ; 2018.

12. Slovic $P$, Fischhoff $B$, Lichtenstein $S$. Facts and fears: understanding perceived risks. In: R.C. Schwing RC, Albers WA, editors. Societal Risk Assessment.New York: Plenum Press; 1980, p. 181-214.

13. Boholm A. Comparative studies of risk perception: a review of twenty years of research. J Risk Res. 1998;1(2):135-63.

14. Foucault M. Em defesa da sociedade. São Paulo: Martins Fontes; 2005. 